\title{
MATERIAL INSTRUCIONAL DE EDUCAÇÃO AMBIENTAL: INSTRUMENTO DE GESTÃO PÚBLICA EM CURITIBA, PR
}

\author{
Samira El Ghoz Leme* \\ Maclovia Corrêa da Silva**
}

\section{Resumo}

O presente artigo recupera registros históricos de políticas públicas da coleta seletiva de resíduos sólidos domiciliares, os quais contribuem para a análise da aplicabilidade e respostas às demandas por materiais instrucionais de Educação Ambiental, na Secretaria Municipal do Meio Ambiente em Curitiba, PR. Foca-se no relato de experiência de criação de diálogos entre setores, originados pelo Guia do Projeto Ecocidadão, recurso pedagógico concebido para a formação de multiplicadores. O Museu de História Natural do Capão da Imbuia é o berço das ações curitibanas de Educação Ambiental, que versavam, em 1970, sobre a conservação da flora e fauna. Mais tarde, nos anos 1980, elas se expandiram para o cotidiano urbano por meio de programas e projetos comunitários. Cresceu a importância dos Materiais Instrucionais para dialogar com as interfaces sociais, culturais, econômicas, ecológicas e políticas. Nesse processo, concluiu-se que os Materiais Instrucionais são instrumentos articuladores de educação e comunicação interinstitucional.

Palavras-chave: Educação ambiental. Materiais instrucionais. Política pública. Diálogos interinstitucionais.

* Mestre pelo Programa de Pós-Graduação em Tecnologia da Universidade Tecnológica Federal do Paraná, Brasil (2009). Bióloga da Prefeitura Municipal de Curitiba (samiraleme@yahoo.com.br).

** Doutora em Arquitetura e Urbanismo pela Universidade de São Paulo, Brasil (2000) Professora do Programa de Pós-Graduação em Tecnologia da Universidade Tecnológica Federal do Paraná - PR (macloviasilva@utfpr.edu.br). 


\section{Introdução}

O início do século XXI remete às questões de adequação de medidas entre as dinâmicas da biosfera ${ }^{1}$ e as condições sociais básicas de sobrevivência da humanidade no planeta Terra. Para essa reorientação há necessidade de políticas que possibilitem a participação efetiva e democrática dos cidadãos na tomada de decisões, em nível internacional e local, de modo a ampliar as esferas de cooperação entre os povos para a construção de sociedades sustentáveis².

Uma forma de concretizar esse movimento é o desenvolvimento de ações, projetos e programas de Educação Ambiental (EA), formal ${ }^{3}$ e não-formal ${ }^{4}$, que incentivem objetivos, interesses e significados comuns às práticas cotidianas locais e que considerem a Terra como "um sistema único e auto-regulador composto de componentes físicos, químicos, biológicos e humanos" (LOVELOCK, 2006, p. 35). Nesse sentido, Viezzer e Ovalles (1995, p. 20) argumentam que

A Educação Ambiental é na verdade uma proposta de filosofia de vida que resgata valores éticos, estéticos, democráticos e humanistas. Ela parte de um princípio de respeito pela diversidade natural e cultural, que inclui a especificidade de classe, de etnia e de gênero. Por isso, uma de suas características é a defesa da descentralização em todos os níveis e a distribuição social do poder, reconhecendo como formas de poder o acesso à informação e ao conhecimento.

A participação ativa das comunidades, empresários, organizações governamentais e não governamentais e outras entidades representativas, no processo de planejamento, tomada de decisões, execução e avaliação contínua das ações e programas desenvolvidos busca um "novo padrão de desenvolvimento socialmente justo, economicamente viável, ecologicamente prudente, politicamente participativo" (RATTNER, 1989 citado por VIEIRA, 1995, p. 118).

A promoção de iniciativas governamentais de Educação Ambiental (EA) para a preservação do meio ambiente para presentes e futuras gerações (BRASIL, 1988) impulsiona a articulação entre os diferentes setores sociais e

1. Biosfera (bio- + -sfera) termo que se refere ao conjunto das partes do planeta Terra onde existe ou pode existir vida.

2. O termo "sociedades sustentáveis" está sendo utilizado a fim de explicitar formas de organização, modos de vida e estilos de desenvolvimento adotados pelos diferentes grupos humanos em virtude da diversidade biofísica e sociocultural existente. Ele foi elaborado por representantes de ONGs de vários países e publicado no Tratado de Educação Ambiental para Sociedades Sustentáveis e Responsabilidade Global, referência para o desenvolvimento da Educação Ambiental no Brasil.

3. EA Formal: processo educativo e informativo desenvolvido em conjunto com os currículos escolares.

4. EA Não Formal: processo educativo e informativo desenvolvido junto à sociedade em geral. 
o cotidiano das pessoas, a ampliação do acesso ao diálogo e a democratização da informação, de modo a favorecer a participação comunitária proativa. Essa participação necessita de compreensão diferenciada quanto à importância de cada pessoa e grupos sociais em seus espaços de convívio e da sustentabilidade de si mesmo, sua casa, seu bairro, sua cidade, seu país, enfim, do Planeta.

Neste sentido, a realização da EA adota a prática de produção de materiais instrucionais por diferentes meios (materiais impressos, rádio, televisão, cinema, websites) e suportes de comunicação (fôlderes, baners, manuais, jornais, revistas, jogos didáticos, vídeos, $\mathrm{CD}$-Rom's, Internet) dirigidos aos diferentes públicos destinatários. Assim, a criação, divulgação e adequação de práticas, técnicas, conhecimentos, métodos, materiais, instrumentos e processos de informação e formação das pessoas em EA motivam a participação pública, prioritariamente coletiva e local, na tomada de decisões sobre as questões ambientais relevantes, respeitando-se a complementaridade entre processos naturais e sociais e entre potencialidades e limitações.

A proposta de inclusão de "novos instrumentos" como a educação, a comunicação, o marketing e a negociação ambientais tem como finalidade aumentar a eficiência dos responsáveis pela gestão ambiental urbana, utilizando-os de forma complementar e integrada aos instrumentos tradicionais (VARGAS; RIBEIRO, 2001, p. 14).

A Educação Ambiental em Curitiba iniciou-se na década de 1970, tendo sido desenvolvida pelo Museu de História Natural do Capão da Imbuia, integrante da Secretaria Municipal de Obras Públicas. Nessa época, as atividades formais eram pontuais e concentravam-se em eventos comemorativos, enfatizando aspectos da flora e fauna. A partir de 1979, houve uma ampliação das ações de conservação ambiental em nível comunitário, bem como continuidade das atividades com escolas. O envolvimento do público adulto passa a ser enfatizado a partir da década de 1980, quando conceitos urbanísticos e preocupações emergentes passam a fazer parte das políticas municipais. Do mesmo modo, foi a criação da Secretaria Municipal de Meio Ambiente (SMMA), em 1986, com a implantação da Gerência de Educação Ambiental vinculada ao Departamento de Pesquisa e Monitoramento Ambiental (atual Centro de Educação Ambiental), que incrementou ações e programas de EA, no âmbito não-formal e formal.

No presente artigo, os materiais instrucionais são instrumentos de diálogo que, quando postos em ação, redimensionam os limites das potencialidades de trocas interinstitucionais. Nas mudanças e na diversidade constroem-se e reconstroem-se leituras de mundo, configurando o pensamento complexo, aberto para desvelar os sentidos da realidade, problematizar as interpretações 
e incorporar valores emancipatórios (LUZZI, 2005). A seguir, um fio condutor, de uso e apropriação do lugar, recupera aspectos históricos das políticas públicas de Educação Ambiental na cidade de Curitiba, PR, colaborando para responder duas questões norteadoras do texto: De que forma os materiais instrucionais apoiam as práticas de Educação Ambiental no sentido de fomentar os diálogos interinstitucionais? E quais meios de aplicabilidade e de repostas às demandas por material instrucional, intitulado "Guia do Projeto Ecocidadão" (CURITIBA, 2009), singularizam os processos de educação e comunicação?

\section{Inciativas de gestão pública dos resíduos sólidos domiciliares}

O planejamento das cidades e a gestão ambiental estão intrinsecamente ligados, envolvendo aspectos objetivos e subjetivos. Assim, a realização de projetos, como a criação de áreas verdes, proteção do patrimônio natural e cultural, promoção de energia limpa, proteção da biodiversidade, redução e reciclagem de resíduos, promoção da educação ambiental, entre outros, podem contribuir para a participação das pessoas e grupos sociais no estabelecimento de parâmetros de políticas públicas de desenvolvimento urbano e a produção de novos sentidos civilizatórios (BRASIL, 2001). Esses princípios estão presentes no Estatuto das Cidades $(2001)^{5}$, que prioriza os planos diretores.

[...] o conceito de que todo planejamento, por ser uma atividade do Estado, tem necessariamente um caráter político. Tratar de planejamento significa tratar de política, fato do qual não se pode ou não se deve esquivar. Porém é importante afastar, inicialmente, o risco do tecnicismo, em que se confunde a técnica de produção do planejamento com os interesses que efetivamente conduzem este processo e moldam ou preestabelecem seus objetivos e conteúdos (JORGE, 2004, p. 737).

A promoção da qualidade de vida, principalmente, relacionada à felicidade e bem-estar nas metrópoles e megalópoles, apresenta uma gama de significados e sentidos que mudam ao longo do tempo, incluindo desde a

5. O Estatuto das Cidades é a denominação dada à Lei Federal n ${ }^{\circ}$ 10.527/2001 (BRASIL, 2008), que estabeleceu as diretrizes gerais da política urbana, visando ordenar o pleno desenvolvimento das funções sociais da cidade e da propriedade urbana. Instituiu diversos instrumentos, como o plano diretor, estudo prévio de impacto ambiental (EIA), estudo prévio de impacto de vizinhança (EIV), entre outros. O plano diretor é o instrumento básico da política de desenvolvimento e expansão urbana, sendo obrigatório para cidades com mais de 20 mil habitantes ou integrantes de região metropolitana e aglomerações urbanas. Disponível em: <(http://www.planalto.gov.br/CCIVIL/Leis/LEIS_2001/L10257.htm)>. Acesso em: 24 set. 2008. 
satisfação das necessidades humanas básicas e oferta de infra-estrutura e serviços até a necessidade de estima, aceitação, reconhecimento, e respeito nos espaços de convivência humana. Vargas e Ribeiro (2001) apontam quatro componentes da qualidade ambiental urbana: espaciais (relacionados ao uso e ocupação do solo), biológicos (referentes à saúde, segurança), sociais (ligados à organização comunitária, culturais, realização pessoal e profissional) e econômicos (voltados às oportunidades de emprego, custo de vida, produtividade).

O modelo de desenvolvimento e o modo de vida atual estão caracterizados pelo aumento acelerado da população, produção e consumo de bens descartáveis e serviços e geração de resíduos sólidos. O gerenciamento integrado desses resíduos visa a redução dos impactos ambientais negativos decorrentes da exponencial e variada quantidade de resíduos gerada pelas atividades humanas e o seu tratamento adequado.

Segundo a Pesquisa Nacional de Saneamento Básico (PNSB) - 2000, realizada pelo IBGE (INSTITUTO BRASILEIRO DE GEOGRAFIA E ESTATÍSTICA, 2009), que mapeou os serviços de abastecimento de água, drenagem urbana, esgotamento sanitário e de lixo nos municípios brasileiros, houve uma significativa melhora na prestação do serviço de coleta de lixo no País, visto que os dados obtidos na PNSB - 1989 apontavam que 76\% do lixo gerado pela população brasileira ficavam a céu aberto (JARDIM et al., 1995).

Em 2000, o lixo produzido diariamente no Brasil chegava a 125.281 toneladas, sendo que $47,1 \%$ eram destinados a aterros sanitários, $22,3 \%$ a aterros controlados e apenas 30,5\% a lixões. Ou seja, mais de $69 \%$ de todo o lixo coletado no Brasil estaria tendo um destino final adequado, em aterros sanitários e/ou controlados (IBGE, 2000).

Em Curitiba, a limpeza pública urbana é um serviço de competência exclusiva do Poder Público Municipal, por meio do Departamento de Limpeza Pública da Secretaria Municipal do Meio Ambiente. A Prefeitura, objetivando o gerenciamento eficaz da coleta e disposição final dos resíduos sólidos, disponibiliza diversos serviços à população, entre eles o de Coleta de Resíduos Sólidos Domiciliares (Coleta Convencional), Coleta de Resíduos Sólidos Recicláveis (Lixo que não é Lixo), Coleta de Resíduos Vegetais e Coleta de Resíduos Perigosos ou Tóxicos, o Programa Câmbio Verde, o Serviço de Varrição Manual e Mecânica e o de Limpeza de Feiras-Livres (CURITIBA, 2009).

A Coleta Seletiva de Resíduos Domiciliares ou "Programa Lixo que não é Lixo", marco do tratamento diferenciado de resíduos sólidos domiciliares em Curitiba, baseia-se na separação pela população dos materiais recicláveis como papel, metal, plástico e vidro, entre outros, gerados nas residências, 
estabelecimentos comerciais, industriais e prestação de serviços, em volumes e características que estejam em conformidade com a legislação municipal ${ }^{6}$. Entretanto, nessas duas décadas, outras iniciativas públicas dirigidas aos resíduos sólidos recicláveis foram implantadas e vêm sendo desenvolvidas, como o Programa Câmbio Verde, de coleta de óleo animal e vegetal usado.

Com o lançamento do "Programa Lixo que não é Lixo", em 1989, aumentou a quantidade de resíduos recicláveis disposta para a coleta e também o número de catadores que recolhiam esses materiais. Algumas iniciativas municipais têm sido desenvolvidas visando à melhoria das condições de vida dos catadores de materiais recicláveis informais.

Anteriormente, em 1982, houve iniciativas de ações coordenadas pela Secretaria de Desenvolvimento Social (SMDS) e em conjunto com a Urbanização de Curitiba S.A. (URBS). Elas resultaram na implantação de um barracão para separação e venda de materiais na Avenida das Torres", a ser coordenado pela primeira "Associação de Catadores de Papel", formada em 1986, e gerenciado pela URBS. Em virtude da solicitação dos catadores da Vila Torres quanto à falta de materiais recicláveis para comercializarem, a Secretaria Municipal do Meio Ambiente (SMMA), através do Serviço de Educação Ambiental Comunitária, desenvolveu um projeto-piloto de "Coleta Programada de Materiais Recicláveis" em 1997. Este buscou organizar a coleta pelos catadores cadastrados em condomínios visando à melhoria da qualidade ambiental da cidade e o aumento da renda dos catadores. Ele não teve continuidade por falta de recursos humanos e financeiros.

Outra iniciativa datada de 1993 foi o "Programa Carrinheiro-Cidadão", pela Fundação de Ação Social (antiga SMDS), em parceria com o Instituto de Pesquisa e Planejamento Urbano de Curitiba (IPPUC), que representou uma nova tentativa de organização dos catadores visando reverter o processo de exploração desses trabalhadores e a minimização dos problemas decorrentes da separação desses materiais em vias públicas, calçadas, terrenos baldios. Em 1997, ele foi reavaliado pelo Poder Público municipal e buscou-se dar

6. O Decreto Municipal n ${ }^{\circ} 983 / 2004$ dispõe sobre a coleta, o transporte, o tratamento e a disposição final de resíduos sólidos no Município de Curitiba estabelecendo a quantidade máxima de 600 litros por semana por habitação unifamiliar ou em cada unidade das habitações em série ou coletivas, dividida pelo número de coletas ofertado pela prefeitura.

7. A Avenida das Torres é o nome dado pela população à Rua Comendador Franco. Avenida larga com muitas torres de energia que liga Curitiba a São José dos Pinhais, ela é um dos limites de um bairro, a Vila das Torres, anteriormente denominado Vila Capanema e Vila Pinto. Está situado em região próxima ao centro da cidade, entre os bairros Rebouças, Jardim Botânico e Prado Velho. É uma região caracterizada por concentrar um grande número de catadores de materiais recicláveis, fato que determinou a implantação de um Parque de Recepção de Recicláveis integrante do Projeto Ecocidadão, que está sendo operacionalizado pela Cooperativa Catamare. 
novo enfoque ao processo de participação dos catadores informais. O resultado se materializou na implantação da Cooperativa dos Trabalhadores de Materiais Recicláveis (RECOOPERE), constituída por 24 sócios fundadores e 140 cooperados.

Entretanto, muitos catadores continuaram desenvolvendo a atividade com o apoio de instituições religiosas, como a Associação de Coletores no Parolim (Instituto Salesiano de Assistência Social) ${ }^{8}$, e de organizações não governamentais, como a Associação dos Coletores de Materiais Recicláveis da Vila Leão - ACARE, apoiada pelo Fórum do Lixo e Cidadania e pela organização não governamental Ecologia Urbana ${ }^{9}$, e a Cooperativa JERA (Cooperativa de Trabalho e Estudo na Área da Toxicomania) no Jardim Moradias Iraí no Cajuru $^{10}$, numa ação conjunta entre Secretaria Municipal de Obras Públicas, a Companhia de Habitação Popular de Curitiba (COHAB) e o Instituto Dedé Mocellin ${ }^{11}$.

Em 1999, a Secretaria Municipal do Meio Ambiente, em conjunto com a Fundação de Ação Social e a Secretaria Municipal de Saúde, realizaram uma pesquisa em toda a cidade, a fim de subsidiar o planejamento de ações visando à melhoria de condições dos catadores. Essa pesquisa com 2.769 catadores entrevistados revelou, em linhas gerais, que $41,56 \%$ possuíam idade entre 20 e 39 anos e atuavam como catadores há mais de cinco anos, sendo $71,36 \%$ do sexo masculino e $28,64 \%$ do sexo feminino (ERTHAL, 2005).

Em 2005, foi iniciada a proposta do Comitê de Cidadania, sob a coordenação da Secretaria Municipal do Meio Ambiente (SMMA), que visava à implantação de nove comitês, um em cada administração regional ${ }^{12}$, como espaço permanente de discussão de problemas e potencialidades da categoria. O objetivo era contribuir com a transformação social dos catadores, visando conquistar a sua dignidade, tendo como consequência a melhoria ambiental

8. Instituto Salesiano de Assistência Social, instituição pertencente à Rede Salesiana de Ação Social da Inspetoria São Pio X com sede em São Paulo, juntamente com outras instituições nos Estados do Rio Grande do Sul, Santa Catarina e Paraná.

9. Ecologia Urbana (EU) é uma organização não governamental sem fins lucrativos, certificada como OSCIP, dedicada à preservação ambiental nas cidades. Criada em setembro de 2002, em Curitiba, Paraná, tem como foco os resíduos sólidos (lixo urbano) e os coletores de materiais recicláveis (carrinheiros).

10. Cajuru, um dos 75 bairros que formam Curitiba atualmente. Um dos mais antigos da cidade. Faz divisa com os bairros Capão da Imbuia, Jardim das Américas, Uberaba e com as cidades vizinhas Pinhais e São José dos Pinhais. Abriga um grande número de catadores, sendo uma área priorizada para implantação de um Parque de Recepção de Recicláveis do Projeto Ecocidadão.

11. O Instituto Dedé Mocellin foi criado em 2002 e tem como missão criar oportunidade de conscientização da sociedade e despertar o espírito da responsabilidade social por meio de projetos de educação, preservação ambiental, enfrentamento da pobreza e valorização da vida.

12. Em Curitiba existem atualmente nove Administrações Regionais, espécie de subprefeituras, visando à descentralização administrativa e a prestação e informação de serviços públicos da esfera municipal, estadual e federal para a população. 
da cidade. Os comitês constituir-se-iam em canais de comunicação entre os catadores e a PMC. Foi criado apenas o Comitê na Regional de Santa Felicidade, devido às novas orientações político-administrativas. Os encontros aconteciam uma vez por mês, com participação de técnicos das secretarias municipais da Saúde (SMS), Abastecimento (SMAB), Esporte e Lazer (SMEL), Educação (SME), Meio Ambiente, a Fundação de Ação Social (FAS), Serviço de Apoio às Micro e Pequenas Empresas (SEBRAE), a Associação Batista de Ação Social de Curitiba (ABASC), que fornecia sopa, e a Fazenda Solidariedade $^{13}$, que fornecia o pão que era servido no início da reunião.

Em 2007, o Projeto Ecocidadão foi iniciado pela Prefeitura Municipal de Curitiba num trabalho conjunto através do Comitê Gestor formado pela Secretaria Municipal do Meio Ambiente, Fundação de Ação Social, Fundação Avina ${ }^{14}$, Movimento Nacional dos Catadores de Materiais Recicláveis ${ }^{15}$ e a Aliança Empreendedora ${ }^{16}$. Ele tem como diretrizes o desenvolvimento local sustentável, a inclusão social, o desenvolvimento do associativismo/cooperativismo e a autogestão por parte dos catadores de materiais recicláveis informais (CURITIBA, 2007).

Essa iniciativa visa à implantação até 2011 de 25 locais para o trabalho de catadores organizados em sistema de associações / cooperativas denominadas Parques de Recepção de Recicláveis (PRR). O objetivo é propiciar condições dignas de trabalho e melhoria na renda e na vida dos trabalhadores da coleta informal e, assim, possibilitar melhor qualidade de vida nas suas moradias. Ele tem o propósito de minimizar situações verificadas na pesquisa realizada pela Prefeitura relativa aos catadores em 1999 e que ocorrem até hoje ${ }^{17}$. Os resultados apontaram que ainda é frequente o uso da moradia como depósito e a dependência, muitas vezes, por parte dos catadores, dos proprietários de depósitos de materiais recicláveis quanto ao carrinho e à moradia, a concentra-ção de catadores e depósitos em áreas de fragilidade ambiental e de precariedade habitacional.

13. Fazenda Solidariedade é sede de um programa de reintegração social e profissional de alcoolistas e dependentes de drogas, localizada em Campo Magro, desenvolvido pela Fundação de Ação Social de Curitiba.

14. A Fundação Avina é uma fundação suíça que busca estabelecer parcerias com líderes da sociedade civil e empresariado para o desenvolvimento sustentável da América Latina.

15. Movimento Nacional dos Catadores de Materiais Recicláveis (MNRC) é um movimento social surgido em 1999 que visa organizar os catadores e catadoras de materiais recicláveis pelo Brasil para a valorização deles como categoria de classe trabalhadora.

16. Aliança Empreendedora é uma organização social sem fins lucrativos que realiza projetos de fomento, integração e apoio ao empreendedorismo comunitário, visando à inclusão econômica e social através da geração de trabalho, renda e desenvolvimento local.

17. Em 1999, foi feita uma pesquisa sobre o sistema informal de coleta e destino de recicláveis pelo Departamento de Limpeza Pública da Secretaria Municipal do Meio Ambiente e Secretaria Municipal da Saúde. 
Somam-se a essas situações a atual evidência do aumento do número de catadores e a imagem negativa do catador por parte da população, devido aos conflitos no trânsito, no manuseio de resíduos em locais públicos, nos pontos de classificação, como praças, calçadas, entre outros.

\subsection{Legislação ambiental na gestão pública de resíduos}

A gestão de resíduos sólidos urbanos em nível municipal tem registros de fiscalização datados do início do século XX quanto às ações de fiscalização, quanto à disposição de lixo e animais mortos nas ruas e praças, expressando a relação Limpeza, Higiene e Salubridade Pública. Em 1953, o Código de Posturas e Obras do Município, apresentado na Lei Municipal no 699 (CURITIBA, 1953), já previa o tratamento do lixo hospitalar e proibia o lançamento de lixo nas ruas, conforme diretriz do Plano Agache de Urbanização de Curitiba ${ }^{18}$.

Posteriormente, na década de 1970, essas medidas influenciaram posturas de cunho conservacionista nas políticas urbanas (TRINDADE, 1997), referenciadas posteriormente na Lei Municipal $n^{\circ}$ 7.833, de 1991, que dispõe sobre a Política de Conservação, Recuperação do Meio Ambiente. Nesta, o controle da poluição atmosférica, hídrica, acústica e visual, e a contaminação do solo e a execução de medidas de saneamento básico constituem princípios fundamentais para minimizar os efeitos impróprios, nocivos à saúde, segurança e bem-estar público (CURITIBA, 1991).

Os resíduos sólidos domiciliares no município especificadamente estão abordados na Lei no 8.985 de 1996 (CURITIBA, 1996) e no Decreto Municipal $\mathrm{n}^{\mathrm{o}} 983$ de 2004 (CURITIBA, 2004). Essa lei estabelece a obrigatoriedade de construção de áreas reservadas à coleta seletiva de lixo nos prédios residenciais, comerciais e condomínios fechados, com mais de seis unidades. O Decreto 983 dispõe sobre a coleta, o tratamento e a disposição final de resíduos sólidos em Curitiba, e estipula no artigo $8^{\circ}$ a incumbência do município da remoção, através da coleta, e o dever do gerador de segregar previamente, acondicionar e dispor os resíduos sólidos domiciliares gerados para coleta (CURITIBA, 2004).

Legalmente, a Educação Ambiental (EA) foi instituída como um dos instrumentos para alcançar os objetivos de proteção, preservação e conservação

18. Plano Agache foi o primeiro Plano Diretor de Urbanização de Curitiba, solicitado pela prefeitura da cidade. Ele foi elaborado pelo arquiteto francês Alfred Agache, que foi contratado por uma firma paulista Coimbra Bueno \& Cia. Nesse plano foram estabelecidas diretrizes e normas técnicas para ordenar o crescimento físico, urbano e espacial da cidade, disciplinando o tráfego, organizando as funções urbanas, além de coordenar e zonear as atividades, codificar as edificações, estimulando e orientando desta maneira o desenvolvimento. Disponível em: <http: / /www.casadamemoria.org $>$. Acesso em: 4 jul. 2009. 
do meio ambiente, pela Lei Orgânica de Curitiba de 1990, em seu capítulo VI - do meio ambiente, artigo 190 (CURITIBA, 1990), e pela Lei Municipal n 7.833 de 1991, que estabeleceu a Política Municipal de Meio Ambiente (CURITIBA, 1991). Nessas, a promoção da educação ambiental, visando à conscientização pública, constitui-se entre as competências do Município relativas ao interesse e bem-estar da população para a preservação do meio ambiente (CURITIBA, 1998).

A partir da década de 1990, ela vem sendo exigida como componente integrante de projetos urbanístico-ambientais, tais como a ampliação do sistema de transporte urbano, planos de regularização fundiária e de arborização pública. Isto revela a complexidade urbana e a necessidade da participação ativa entre pessoas e instituições nas reestruturações e redefinição de iniciativas de gestão que implicam políticas e instrumentos políticos, conhecimento científico e o estabelecimento de consensos e parcerias (ALIROL, 2001).

A efetivação das legislações ambientais, que incluem como princípios a precaução e prevenção como formas de manter, controlar ou recuperar os padrões de qualidade do ecossistema local, requer a mobilização comunitária como possibilidade de mudar padrões de consumo e produção, de forma a permitir a redução da geração, a reutilização ou reciclagem dos resíduos sólidos gerados. Desta forma, a Educação Ambiental deve incentivar o envolvimento de grupos comprometidos com as questões ambientais nos processos de planejamento e implantação dos programas e ações que visem promover a qualidade de vida nos aspectos econômicos, socioculturais, ambientais e políticos (PHILIPPI JUNIOR; MALHEIROS, 2005).

Decorrente da implementação dessas legislações, acontece a incorporação das regras, via controle e monitoramento, e a produção de materiais instrucionais específicos que são utilizados, ou distribuídos, nas diferentes ações educativas - palestras, cursos, eventos - como respostas às demandas, internas ou externas. A aplicabilidade desses materiais aproxima as informações das pessoas, permite o desenvolvimento de habilidades, possibilita a mudança de posturas cotidianas voltadas para o bem-estar coletivo.

\section{Materiais instrucionais e diálogos Interinstituicionais}

Os materiais instrucionais de Educação Ambiental medeiam processos ecológicos, socioculturais, tecnológicos, econômicos e políticos, considerando as condições naturais e as formas de percepção e apropriação da natureza.

A Educação Ambiental (EA) tem como seus principais objetivos o fomento à participação e mobilização comunitárias, necessitando, para isso, da difusão e incorporação de novos conceitos e práticas baseadas na aliança sociedade- 
natureza. A difusão dessas informações está voltada à formação de uma consciência crítica de caráter educativo por meio de materiais instrucionais e faz parte da política pública de meio ambiente.

A veiculação de informações, a aquisição de conhecimentos e o desenvolvimento de metodologias de Educação Ambiental de enfoque local aumentaram a partir da Política Nacional de Meio Ambiente (Lei nº 6.938/1981) (BRASIL, 1981), da Constituição Federal (BRASIL, 1988) e da Política Nacional de Educação Ambiental (Lei no 7.975/1999) (BRASIL, 1999), como requisitos para promover a mobilização da sociedade, em nível individual e coletivo. Porém, é preciso que haja uma vinculação entre as legislações e a política.

Tal compreensão política da educação só é legitimada na Modernidade, a partir do momento em que pressupõe que a história das sociedades humanas não é previamente determinada, mas resultante de processos dinâmicos estabelecidos, construídos e transformados por sujeitos históricos: os cidadãos, seja em suas ações individuais ou coletivas (LOUREIRO, 2005, p. 72).

No desenvolvimento dos programas e ações, de modo geral, os materiais impressos como cartazes, cartilhas, boletins informativos, folhetos e panfletos, apesar de a sociedade dispor de outros meios de comunicação, dentre eles jornais, revistas, rádio, televisão, cinema e websites, continuam sendo utilizados. Segundo Dietz e Tamaio (2000, p. 256), “a tendência do público é considerar as mensagens divulgadas nesses materiais como algo absolutamente verdadeiro, e que o leitor pode absorver quando estiver disposto, e voltar a ler ou fazer referência ao material quantas vezes julgar necessário". Entretanto, qualquer que seja o meio de comunicação utilizado, eles disponibilizam conhecimentos e práticas de caráter local, e apresentam quadros que visualizam sociedades sustentáveis. O controle social acontece mediante a participação da população no momento de suas escolhas e tomadas de decisão.

Nesse contexto, a Educação Ambiental tem papel fundamental para a construção, difusão e apropriação de práticas, técnicas, conhecimentos, métodos, materiais, ferramentas, processos voltados para o estabelecimento de novos padrões de atividades na sociedade que sejam embasados na convivência e co-existência da humanidade e dos outros seres vivos no espaço comum chamado Terra. Magozo (2005, p. 425) diz que

a incorporação de uma mudança ética, além de uma mudança paradigmática ou conceitual, proposta pelo ambientalismo depende de processos educativos que tenham clareza do que esta proposição representa. E com que valores trabalha a Educação Ambiental? O primordial é o respeito à vida.

A inclusão das dimensões técnico-científica, jurídico-institucional e ecológico-econômica nos processos pedagógicos fornece argumentos para a 
promoção de mudanças desejadas e propostas para e pelos diferentes setores da sociedade de consumo urbano-industrial e articula relações entre o local e o global. Segundo Silva (1996, p. 48), “a Educação Ambiental aí se insere, no sentido de que se deve produzir atualmente (e se 'reproduzir', como mostra, por exemplo, o conceito de 'multiplicadores' que é utilizado) uma reflexão e uma ação em favor do meio ambiente".

Desta forma, o discurso da educação ambiental ${ }^{19}$ é historicamente determinado e pressupõe uma adequação de linguagem que possibilite o reconhecimento com as falas e ações dos diferentes segmentos sociais. A articulação entre a compreensão da realidade e o posicionamento frente a ela depende do que "Sabemos que os sentidos fazem sentido pra alguém. Não são os sentidos "em si" (ORLANDI, 1996, p. 46). Assim, a produção de materiais instrucionais impressos de Educação Ambiental pressupõe que "alguém diz pra alguém em algum lugar e tempo determinados", de modo que forma e conteúdo trabalham com argumentos que integram o real e o simbólico.

Os Materiais Instrucionais de EA produzidos pela Secretaria Municipal do Meio Ambiente, que representa uma autoridade frente aos cidadãos, estabelecem diálogos, uma vez que são recebidos de forma diferenciada pelos grupos destinatários. Estes abordam processos, relações, conceitos, valores e participação, devendo articular o que o leitor deve saber, o que ele deseja saber, e o que o escritor/autor considera significativo transmitir. Ao mesmo tempo, considera o leitor como parte de uma coletividade, e busca-se tornálo "um novo cidadão que, entre os seus deveres para com essa 'propriedade de todos', leve agora em conta o meio ambiente" (SILVA, 1996, p. 52).

Assim, os Materiais Instrucionais de EA constituem meios para estabelecer o diálogo e verificação dos temas escolhidos com os conhecimentos e saberes a partir de conteúdos e temas ambientais. Orlandi (1996, p. 50) ressalta que “Todo investimento em educação é um investimento no sentido de uma transformação do(s) sujeito(s)".

$\mathrm{Na}$ Prefeitura de Curitiba, diversas iniciativas de produção de materiais educativos relativos à temática ambiental são formuladas pelas Secretarias de Comunicação Social e do Meio Ambiente (SMMA). Estes são idealizados para veicular informações, conceitos e práticas que promovam o entendimento da co-responsabilidade por parte da população na gestão ambiental da cidade.

A confecção dos Materiais de Educação Ambiental pelo Centro de Educação Ambiental (CEA) da SMMA ocorre em função de demandas originadas

19. Discurso da educação ambiental englobando discursos de conhecimento, de informações diversas, de educação doméstica, político (referenciando o público destinatário) e discurso escolar, empresarial e político-administrativo (referente ao emissor). 
pelo próprio setor público e demais setores sociais. A interlocução originada na demanda e oferta de Materiais Instrucionais de EA envolve critérios pluralistas, visto constituir recursos para mediação de diálogos entre os grupos destinatários, como comunidades participantes de programas ambientais desenvolvidos, comunidades científicas, consumidores, grupos organizados de classe, administradores públicos. Na prática, observam-se três tipos mais frequentes de demandas: no setor e entre setores da Secretaria ${ }^{20}$, entre-setores da Prefeitura ${ }^{21}$ e demais instituições públicas, privadas e organizações não governamentais ${ }^{22}$.

O processo de concepção e produção dos Materiais Impressos de EA inicia-se com o diálogo entre os técnicos dos setores envolvidos para os quais o material se destina. Num segundo momento, ocorre a definição inicial e posterior redação de texto abordando conceitos teóricos e orientações de práticas selecionadas de livros, exemplares de outras instituições, referências documentais. As falas dos interlocutores expandem-se com a escrita dos materiais.

O texto inicial é submetido à leitura de técnicos do CEA e de outros setores afins para observações, sugestões e alterações. O texto continua seu trajeto e passa para outros profissionais, que intervêm realizando o processo de comunicação visual mediante a inserção de imagens e formatação do leiaute.

Um novo diálogo se estabelece após a versão ilustrada, quando ocorre nova leitura pelos técnicos de diferentes setores afins e níveis hierárquicos superiores para aprovação e conclusão da arte final. $\mathrm{O}$ momento seguinte, $\mathrm{o}$ de produção gráfica ou de reimpressão dos materiais concebidos, pode ocorrer internamente no CEA ou em estabelecimentos habilitados por processos de licitação, pregão eletrônico ou empenho.

O fornecimento ou distribuição dos Materiais Impressos de EA produzidos como recursos didáticos para articular a participação dos indivíduos ou grupos sociais ocorre quando os cidadãos solicitam Materiais Impressos de EA através do Sistema Integrado de Atendimento ao Cidadão (Fone 156); através do site da prefeitura (www.curitiba.pr.gov.br); por telefone ou pessoalmente no Centro de Educação Ambiental da Secretaria do Meio Ambiente.

20. Os Materiais Impressos de EA produzidos contribuem para a efetivação de diferentes programas e ações ambientais de competência da Secretaria do Meio Ambiente, como o Programa Biocidade, Câmbio Verde e eventos comemorativos.

21. A EA é um componente em diversos programas intersetoriais, como, por exemplo, Linha Verde (ampliação e modernização do sistema viário e de transporte, transformando trecho da antiga rodovia federal BR-116 em uma avenida urbana), e Programas de EA em processos de Regularização Fundiária. Nesses, a produção de Materiais Impressos de EA é prevista para os processos de mobilização, informação e sensibilização dos beneficiários dos programas.

22. A distribuição e, algumas vezes, a produção e reprodução de Materiais Impressos de EA ocorrem para serem usados em ações educativas específicas e campanhas educativas (palestras, eventos, material didático complementar). 


\section{0 Gpec: Guia para Multiplicadores de Catadores do Projeto Ecocidadão}

No Projeto Ecocidadão está previsto o Programa de formação das equipes operacionais dos Parques de Recepção de Recicláveis - PRR e catadores, constituindo uma ação conjunta entre a Secretaria Municipal do Meio Ambiente, entidade executora e entidade selecionada pelo Comitê de Fomento à Reciclagem.

Para a primeira fase de capacitação foi elaborado um modelo de um manual intitulado Guia para Multiplicadores de Catadores de Materiais Recicláveis de Curitiba (GPEC) (CURITIBA, 2009). Para a segunda fase, a Aliança Empreendedora está desenvolvendo uma formação continuada sistemática, com as equipes operacionais e catadores por profissionais contratados por essa ONG. Há também a realização de reuniões semanais junto aos catadores, momentos em que são avaliados os passos que estão sendo construídos pelas associações no decorrer do projeto. Através dos pontos trazidos pelos catadores, e às vezes pelas equipes operacionais dos PRR's, buscam-se alternativas visando o cultivo de princípios para o fortalecimento da organização dos catadores.

O Guia do Projeto Ecocidadão (GPEC) (2009) é um guia de formação em Educação Ambiental para os multiplicadores que atuam com os catadores de materiais integrantes do projeto. Ele facilita o entendimento para as equipes de multiplicadores de que os princípios de EA estão desenvolvidos na forma de organização do trabalho de catação de materiais recicláveis e perpassam pelos temas de segurança, saúde, trabalho em equipe, e valorização pessoal. Ele busca estabelecer o diálogo interinstitucional e contém textos que trabalham aspectos do cotidiano do catador de materiais recicláveis.

A versão preliminar do Guia (GPEC) (2009) foi escrita por uma equipe de técnicos vinculados à Secretaria Municipal do Meio Ambiente e às ONG que já trabalham com a questão de materiais recicláveis. O documento, dirigido às equipes de educadores (multiplicadores) que administram e gerenciam os parques, subsidia ações de educação ambiental e gestão dos resíduos sólidos selecionados nos sete Parques de Recepção de Recicláveis do Projeto Ecocidadão existentes, e dos próximos 18 a serem implantados até 2011.

O conteúdo sugere atividades nos seguintes aspectos:

Valorização pessoal e auto-estima do catador - trata de aspectos quanto às relações estabelecidas consigo mesmo, com o outro e com o mundo.

A organização da atividade de coleta (a carrinhada) e a reciclagem - traz reflexões sobre o entendimento de meio ambiente, a organização da atividade de coleta de materiais como possibilidade de trabalho e de realização pessoal. Engloba aspectos relacionados à importância do catador no ciclo de vida do produto e da reciclagem. 
Saúde e segurança do catador no trabalho e no trânsito - desenvolve conceitos e práticas de cuidado e minimização de riscos e acidentes existentes na atividade de catação a serem incorporadas pelos multiplicadores e catadores.

Trabalho em equipe e o associativismo - apresenta subsídios teórico-práticos de fomento à organização de grupos em associações ou cooperativas de catadores de materiais recicláveis como possibilidade de melhoria de vida pessoal e profissional por parte deles.

O GPEC (2009), nos seus quatro módulos temáticos, se singulariza enquanto Material Instrucional na medida em que suas partes se "entrelaçam" como forma de demonstrar o princípio da interdependência entre os diferentes componentes de sistemas naturais ou culturais. Outro pressuposto-chave do material é incentivar o respeito ao outro, no sentido de que "todos somos aprendizes", fomentando, assim, atitudes de acolhimento, de escuta, de troca e respeito mútuo entre os participantes do projeto. Assim, o texto foi pensado para propiciar um diálogo frequente entre o emissor e o leitor mediante os conteúdos e práticas propostas pelo material. O texto tem um caráter abrangente, linguagem acessível, uma abordagem lúdica e positiva das temáticas, de forma a favorecer a construção conjunta de saberes e conhecimentos. Ele responde às demandas globais dos catadores que buscam a organização da classe e melhoria de condições de vida.

\section{Conclusão}

A recuperação dos registros históricos das políticas púbicas para a questão dos resíduos sólidos contribui para o entendimento da amplitude e complexidade da situação ambiental urbana. Embora o Material Instrucional seja concebido para públicos específicos, há grupos de pessoas envolvidas no processo. No caso da coleta seletiva, o início da aplicabilidade dos pressupostos de Educação Ambiental está na geração, separação e disposição para coleta dos resíduos. As informações do Material que foi criado para orientar as equipes operacionais dos Parques de Recepção de Recicláveis de Curitiba estão contidas no processo de gestão compartilhada. Separar para comercializar e separar para descartar são funções diferentes, mas fazem parte do mesmo processo produtivo, de atitudes de proteção ambiental e de respeito à vida. Essas atitudes extrapolam a gestão pública dos resíduos e demandam as práticas orientadoras da Educação Ambiental. Fazer parte de programas e projetos comunitários significa dialogar com as iniciativas públicas e suas interfaces sociais, culturais, econômicas, ecológicas, políticas. 
Do mesmo modo, a realidade dos catadores impulsionou esses pressupostos do material instrucional intitulado Guia do Projeto Ecocidadão. O social relacionado ao reconhecimento e valorização dos catadores como cidadãos e trabalhadores. O econômico dirigido ao fomento à organização em associações e cooperativas de forma que favoreçam a cidadania. $\mathrm{O}$ aspecto ecológico relativo ao incremento da reciclagem, possibilitando economia de matérias primas e energia na produção, ao integrar os processos de tratamento e disposição final dos resíduos sólidos urbanos gerados no município. O político relacionado ao estímulo à organização, mobilização e motivação dos catadores para a formação de grupos organizados.

O GPEC, enquanto material de Educação Ambiental, sugere atividades que esclarecem ao multiplicador como ele pode dialogar diretamente com um público específico que vai desenvolver um segmento da catação de resíduos sólidos urbanos em Parques de Recepção de Recicláveis (PRR). Essas pessoas que vão participar dos grupos a serem formados nos PRR's, comumente denominados barracões, precisam não somente entender de gestão de trabalho, mas compreender como a Educação Ambiental pode fomentar práticas socioeducativas fundamentadas no pensamento complexo.

\section{Referências}

ALIROL, Philippe. Como iniciar um processo de integração. In: VARGAS, Heliana; RIBEIRO, Helena (Org.). Novos instrumentos de gestão ambiental urbana. São Paulo: Edusp, 2001. p. 21-42.

BRASIL. Política Nacional do Meio Ambiente. 1981. Disponível em: <www.planalto. gov.br/ccivil_03/Leis/L6938.htm>. Acesso em: 24 set. 2008.

. Política Nacional de Educação Ambiental. 1999. Disponível em: < www. planalto. gov.br/ ccivil/Leis/L9795.htm>. Acesso em: 24 set. 2009.

. Constituição Federal do Brasil. 1988. Disponível em: <www.planalto. gov.br/ ccivil_03/.../constituiçao.htm>. Acesso em: 5 out. 2007.

. Estatuto das cidades: Lei Federal $\mathrm{n}^{\circ}$ 10.257. 2001. Disponível em: $<$ Www.planalto.gov.br/ccivil_03/LEIS / LEIS_2001/L10257.htm>. Acesso em: 24 set. 2008.

CURITIBA. Secretaria Municipal do Meio Ambiente (SMMA). Coletânea de Legislação Ambiental de Curitiba: que dispõe sobre a política de proteção, conservação e recuperação do meio ambiente. Curitiba: Artes Gráficas Unificado, 1998.

1953.

. Lei Municipal $n^{\circ}$ 699. Estabelece o Código de Posturas e Obras do Município. 
CURITIBA. Lei Orgânica. Institui a Educação Ambiental como um dos instrumentos para alcançar proteção, preservação e conservação do meio ambiente. 1990. In: cado, 1998. Coletânea de Legislação Ambiental de Curitiba. Curitiba: Artes Gráficas Unifi. Secretaria Municipal do Meio Ambiente (SMMA). Lei no 7.833 de 19 de dezembro de 1991. Dispõe sobre a política de proteção, conservação e recuperação do meio ambiente. In: . Coletânea de Legislação Ambiental de Curitiba. Curitiba: Artes Gráficas Unificado, 1998.

Secretaria Municipal do Meio Ambiente (SMMA). Lei $\mathrm{n}^{\circ}$ 8.985. 1996. In: cado, 1998.

Coletânea de Legislação Ambiental de Curitiba. Curitiba: Artes Gráficas Unifi-

. Decreto Municipal $n^{\circ} 983$ de 26 de outubro de 2004. Regulamenta a Lei ${ }^{\circ}$ 7.833/1991 dispondo sobre a coleta, o transporte, o tratamento e a disposição final de resíduos sólidos em Curitiba. 2004. Disponível em: <www.curitiba.pr. gov.br>. Acesso em: 23 maio 2009.

Secretaria Municipal do Meio Ambiente (SMMA). Projeto Ecocidadão: reciclagem e inclusão total. Curitiba, 2007 (não publicado).

. Secretaria Municipal do Meio Ambiente (SMMA). Guia para multiplicadores dos catadores de materiais recicláveis de Curitiba: Projeto Ecocidadão. Curitiba, 2009 (não publicado).

DIETZ, Low Ann; TAMAIO, Irineu (Org.). Aprenda fazendo: apoio aos processos de Educação Ambiental. Brasília, DF: WWF Brasil, 2000.

ERTHAL, Maria A. Histórico do coletor do material reciclável de Curitiba. Curitiba, 2005 (não publicado).

INSTITUTO BRASILEIRO DE GEOGRAFIA E ESTATÍSTICA. Pesquisa Nacional de Saneamento Básico: 2000. Disponível em: <www.ibge.gov.br>. Acesso em: 23 maio 2009.

JARDIM, Niza (Coord.) et al. Lixo municipal: manual de gerenciamento integrado. São Paulo: Instituto de Pesquisas Tecnológicas/Cempre, 1995.

JORGE, Wilson E. Política e planejamento territorial. In: PHILLIPI JUNIOR, Arlindo; ROMÉRIO, Marcelo A; BRUNA, Gilda C. Curso de gestão ambiental. São Paulo: Manole, 2004. p. 737-758.

LOUREIRO, Carlos F. Educação ambiental: repensando o espaço da cidadania. São Paulo: Cortez, 2005.

LOVELOCK, James. A vingança de Gaia. Trad.: Ivo Korytowski. Rio de Janeiro: Intrínseca, 2006.

LUZZI, Daniel. Educação Ambiental: pedagogia, política e sociedade. In: PHILIPPI JUNIOR, Arlindo; PELICIONI, Maria Cecília (Org.). Educação ambiental e sustentabilidade. Barueri, SP: Manole, 2005. p. 381-400. 
MAGOZO, Helena Maria Campos. Subjetividade no processo educativo: contribuições da psicologia à educação ambiental. In: PHILIPPI JUNIOR, Arlindo; PELICIONI, Maria Cecília (Org.). Educação ambiental e sustentabilidade. São Paulo: Manole, 2005. p. 421-436.

ORLANDI, Eni P. O discurso da educação ambiental. In: TRAJBER, Rachel; MANZOCHI, Lúcia (Coord.). Avaliando a educação ambiental no Brasil: materiais impressos. São Paulo: Instituto Ecoar para a Cidadania, 1996. p. 37-47.

PHILIPPI JUNIOR, Arlindo; MALHEIROS, Tadeu F. Saúde ambiental e desenvolvimento. In: PHILIPPI JUNIOR, Arlindo; PELICIONI, Maria Cecília (Org.). Educação ambiental e sustentabilidade. São Paulo: Manole, 2005. p. 59-84.

SILVA, Telma D. O cidadão e a coletividade: as identificações produzidas no discurso da educação ambiental. In: TRAJBER, Rachel; MANZOCHI, Lúcia H. Avaliando a educação ambiental no Brasil: materiais impressos. São Paulo: Instituto Ecoar para a Cidadania, 1996. p. 47-58.

TRINDADE, Etelvina Maria de Castro (Coord.). Cidade, homem e natureza: uma história das políticas ambientais de Curitiba. Curitiba: Universidade Livre do Meio Ambiente, 1997.

VARGAS, Heliana; RIBEIRO, Helena. Qualidade ambiental urbana: ensaio de uma definição. In: (Org.). Novos instrumentos de gestão ambiental urbana. São Paulo: Edusp, 2001. p. 13-19.

VIEIRA, Paulo. A problemática ambiental e as ciências sociais no Brasil (1980-1990). In: HOGAN, Daniel; VIEIRA, Paulo (Org.). Dilemas socioambientais e desenvolvimento sustentável. Campinas: Edunicamp, 1995. p. 103-147.

VIEZZER, Moema; OVALLES, Omar. Manual latino-americano de educação ambiental. São Paulo: Gaia, 1995. 


\section{Instructional material for environmental education: public management instrument in Curitiba (Brazil) \\ Abstract}

The present paper recuperates the historical records of public policies of selective collecting of domestic solid residues which contribute to the analysis of applicability and responses to the demands for Environmental Education Instructional Material at the Municipal Environmental Department in Curitiba, Paraná (Brazil). It focuses on the report of the experience of dialogue creation among sectors, originated by the "Guide of the Ecocitizen Project", a pedagogical tool conceived for the training of multipliers. The Capão da Imbuia Natural History Museum is the birthplace of Curitiba's Environmental Education which, in the 1970's, dealt with the fauna and flora conservation. Later on, in the 1980's, they expanded to the urban daily life by means of community programs and projects. The importance of Instructional Materials to dialogue with the social, cultural, economical, ecological and political interfaces increased. Throughout this process, the conclusion is reached that Instructional Materials are instruments of articulation for educational and inter institutional communication.

Keywords: Environmental education. Instructional material. Public policy. Inter institutional dialogues.

\section{Matériaux instructifs pour l'éducation de l'environnement : instrument de gestion publique à Curitiba (Paraná, Brésil) Résumé}

L'article qui suit récupère les registres historiques des politiques publiques de la collecte sélective de résidus solides domiciliaires, lesquels contribuent à l'analyse de l'applicabilité et les réponses aux demandes pour des matériaux instructifs en Éducation de l'Environnement dans le Secrétariat Municipal de l'environnement à Curitiba, Paraná (Brésil). Il focalise sur le rapport de l'expérience de la création de dialogues, entre secteurs, dont l'origine est attribuée au Guide du Projet Écocitoyen, aide pédagogique conçu pour la formation de multiplicateurs. Le Musée de l'Histoire Naturelle du Capão da Imbuia est le berceau des actions de Curitiba en matière d'Éducation Environnementale qui, en 1970, versaient sur la conservation de la flore et faune. Plus tard, dans les années 1980, elles se sont étendues au quotidien urbain au travers de programmes et projets communautaires. L'importance des matériaux pédagogiques pour dialoguer avec les interfaces sociales, culturelles, économiques, écologiques et politiques a augmenté. Dans ce processus, l'on conclu que les matériaux pédagogiques sont des instruments articulateurs de l'éducation et de la communication interinstitutionnelle.

Mots clefs : Éducation de l'environnement. Matériaux pédagogiques. Politique publique. Dialogues interinstitutionnels. 


\section{Material instruccional de educación ambiental: instrumento de gestión pública en Curitiba (Brasil) \\ Resumen}

El presente artículo recupera registros históricos de políticas públicas de colecta selectiva de residuos sólidos domiciliares, los cuales contribuyen para el análisis de la aplicabilidad y respuestas a las demandas por materiales instruccionales de educación ambiental, en la Secretaría municipal del medio ambiente en Curitiba, Paraná (Brasil). Enfoca el relato de experiencia de creación de diálogos, entre sectores, originados por el guía del proyecto ecociudadano, recurso pedagógico concebido para la formación de multiplicadores. El museo de historia natural del Capão da Imbuia es la cuna de las acciones curitibanas de educación ambiental que versaban, en 1970, sobre la conservación de la flora y fauna. En los años 1980, ellas se expandieron para el cotidiano urbano por medio de programas y proyectos comunitarios. Creció la importancia de los materiales instruccionales para dialogar con las interfaces sociales, culturales, económicas, ecológicas y políticas. En ese proceso, se concluyó que los materiales instruccionales son instrumentos articuladores. De educación y comunicación interinstitucional.

Palabras clave: Educación ambiental. Materiales instruccionales. Política pública. Diálogos interinstitucionales. 